\title{
REFLEXIONES DE FRANCISCO AYALA SOBRE EL EXILIO INTELECTUAL ESPAÑOL
}

\author{
POR
}

JULIA CELA

Universidad Complutense de Madrid

A través del pensamiento del escritor español Francisco Ayala - exiliado en la Argentina en la década de los años cuarenta- se analiza el concepto de exilio y exiliado desde la perspectiva del intelectual, que se encuentra obligado a producir fuera de su país, perdiendo así el destinatario principal de su obra: el público español.

\section{Concepto del término EXILIO}

La palabra española exilio procede de la latina exilium, y se ha introducido en nuestro país como un galicismo moderno en vez de utilizar el antiguo término destierro, que significa expulsar a una persona de un lugar o territorio determinado, para que resida fuera de él de forma temporal o perpetua. En realidad el destierro es un traslado desde la propia tierra a otra de adopción, y a la vez un desplazamiento obligatorio que viene determinado por la expulsión. La palabra exilio -según las cuatro acepciones que recoge la Real Academia Española de la Lengua-, tal vez sea la que mejor exprese la realidad que le acaece al exiliado en los dos últimos siglos de historia española. En primer lugar, como la separación de una persona de la tierra en que vive; segundo, como una expatriación, generalmente por motivos políticos; tercero, como el efecto de estar 
exilada una persona; y por último, también se denomina exilio al lugar donde vive el exiliado (1).

A veces el término exiliado se ha confundido con otros casi sinónimos, que han sido en muchas ocasiones utilizadas para dar la misma definición y con el mismo fin, como el de emigrado o transterrado; siendo utilizado en general por los historiadores y estudiosos del tema el término exiliado para contextos políticos, emigrado para contextos personales y económicos, y transterrado - una invención de José Gaos, adoptada por Max Aub y otros autores- para el contexto filosófico de lealtad a la propia tierra espiritual: la propia lengua. Y a estas tres acepciones habría que añadir otras, eso sí, menos utilizadas que intentan definir la misma acción, como: desterrados, peregrinos, despatriados y transplantados (2).

El exiliado, sujeto agente de la acción, es una persona que se ve forzada a abandonar su país o a permanecer fuera de sus límites por miedo a persecuciones; y no debemos olvidar que también es alguien que espera regresar cuando las circunstancias se lo permitan.

El término exiliado -que elegimos como el más utilizado y el que mejor recoge la definición- se convirtió durante la dictadura franquista, en una palabra que evocaba asociaciones contradictorias según quienes la utilizaran. Para los vencedores era sinónimo de traición, de un grupo de personas a los que ya no consideraban auténticos españoles. Este punto de vista además mezclaba sentimientos de hostilidad y desprecio con indiferencia, y la creencia de que esta ausencia era permanente y sin ningún impacto en el futuro del país. Para los vencidos, exiliado significaba campos de concentración franceses, sufrimientos físicos como refugiados, injusticia mientras comenzaba otra nueva vida, el viaje a lejanas tierras o repatriación después de la guerra, en algunos casos; pero en todos significó el dolor de dejar de existir para la otra España, la que seguía afincada en su país. «En resumen, la España franquista se horrorizó de la mancha del exilio y declaró tabú la importación de sus publicaciones. La España republicana se desvane-

(1) Diccionario de la Real Academia Española de la Lengua, Madrid, Espasa-Calpe, 1986, tomo I, pág. 619.

(2) Paul ILlie, Literatura y exilio interior, Madrid, Fundamentos, 1981. 
ció en el recuerdo y los partidarios se alejaron mentalmente de la realidad geográfica» (3).

Según José Luis Abellán, estudioso del fenómeno del exilio y sus protagonistas, no se puede denominar exilio a un éxodo por muy masivo que éste sea, en un momento dado de la historia de un país; si bien éste no viene acompañado de una voluntad política propia de huir del país de origen y de una coacción de carácter político o parapolítico. En relación con el exilio de 1939, Abellán sólo considera propiamente exiliados a aquellos cuya salida de España se produjo por adscripción al régimen republicano establecido en abril de 1931, o al menos aquellos para quienes el régimen franquista resultaba intolerable (4).

Para Francisco Ayala el término exilio hay que despojarlo de todo halo de dramatismo y mitificación que ha llegado a alcanzar en muchos autores, tanto activos como pasivos del hecho en sí; para constituirse no tanto en una experiencia concreta, como en la idea misma del exilio; no tanto en las condiciones reales en que cada uno se encontrase viviendo fuera de España, como en la conciencia de una ausencia definitiva «-tan definitiva, que si uno volviese, volvería a un país muy diferente del que ha sido el suyo-. La idea del exilio sería, pues, para quienes abandonamos España conclusión y resumen de la catástrofe histórica padecida por todos los españoles, por nosotros, y también por quienes se quedaron dentro, en exilio interior o cautiverio" (5).

Ayala dibuja cuatro perfiles para clasificar a los intelectuales exiliados: el primero de ellos, el que se puede considerar de los privilegiados, fueron aquellos que se establecieron en países de habla española con unas condiciones culturales muy similares, que facilitaron su desenvolvimiento intelectual y humano, e incluso en muchos casos potenciaron un nuevo desarrollo para su pensamiento gracias a las favorables condiciones del medio ambiente en el que pudieron desarrollar su trabajo. Pese a las

(3) Idem.

(4) José Luis Abellán, Panorama de la filosofía española actual. Una situación escandalosa, Madrid, Espasa-Calpe, Selecciones Austral, n.o 32, 1978, pág. 106.

(5) Francisco Ayala, «La cuestionable literatura del exilio», en El escritor y su siglo, Madrid, Alianza Tres, 1990, págs. 224-237. 
limitaciones propias de ser exiliado y de vivir en otro país, en definitiva de ser extranjero, los intelectuales que emigraron a Latinoamérica encontraron en la comunidad local una puerta abierta, que aprovecharon para desarrollar su tarea como intelectuales y hombres de pensamiento, expresando sus opiniones como tales cuando la situación así se lo permitía.

Un segundo perfil, lo constituyen aquellos exiliados que se establecieron en tierras de habla no española. Éstos, al contrario que sus compatriotas que vivían en países de América Latina, se establecían en enclaves hispanófonos aislados o en enclaves académicos, siendo su percepción de la realidad histórica que) les circunda mediatizada por una cultura extranjera. Son aquellos españoles que fueron a establecerse en los Estados Unidos o se quedaron en Inglaterra o Francia, los que tenían que hablar e intentar pensar en otro idioma, los que vivían el complejo cultural de una comunidad extraña; en fin, los que se sintieron a perpetuidad refugiados extranjeros. «De manera curiosamente análoga a la de quienes viven en el secuestro de España, los intelectuales acogidos a tierras de otro idioma han de aplicarse a la evocación, a la erudición, o escapar por las vías de un desligado subjetivismo, sin salida al mundo" (6).

El tercer perfil lo constituye el exiliado que dramatiza su situación, que la convierte en un calvario y que mentalmente se siente "un alma en pena» consumido por la nostalgia. Este es el expatriado que mitifica su nueva forma de vida con un halo romántico de pesimismo dramático.

Y por último, el cuarto perfil lo protagonizaría el exiliado perdido, aquel que convierte el destierro -según palabras de Ayala- en incesante peregrinación sin dar en playa donde asentar sus reales, o árbol donde ahorcarse. Pero todos ellos, los privilegiados por vivir en un país de habla hispana, los que se establecieron en países de otro idioma y cultura muy diferente, los que se encuentran perdidos en su incesante peregrinar o aquellos consumidos por la nostalgia, todos ellos al menos se encuentran en alguna parte, en algún lugar del mundo desde cuya perspectiva pueden ver el conjunto (7).

(6) Francisco AyAla, «Para quién escribimos nosotros», [5], págs. 197-223.

(7) Idem.

R. I., 1996, n.o 207 
También tendríamos que añadir un quinto perfil, el del exiliado interior: aquellos españoles que no se encuentran desterrados, que no viven lejos de su patria, pero que sí se encuentran exiliados dentro de sus propias fronteras, conviviendo en su propia lengua, pero sin poder expresar sus sentimientos en ésta, sintiéndose en todo momento ajenos y rodeados de extraños en su propio país. Para el investigador Paul Ilie, el exilio interior era primero un aislamiento padecido por diversos grupos con respecto a los otros, y con respecto a toda una cultura; segundo era una asfixia parcial de toda la cultura, que se había separado a sí misma de varias arterias que le daban vida; y por último era un estado psicológico, experimentado individual y colectivamente (8).

Ayala también reconoce este quinto perfil de exiliados, que lo formaron aquellos que se quedaron en el país en palpable desacuerdo con el régimen político imperante, quienes constituyeron el llamado exilio interior.

La guerra civil, y el régimen político que surgió vencedor de ella, ejerció tal violencia en la sociedad española que sus huellas fueron apreciables e incluso inocultables, no sólo en la vida cotidiana sino también en la intelectual, de tal forma que impusieron el exilio -tanto el exilio propiamente dicho, como el llamado exilio interior- a todos aquellos que se dedicaban a actividades políticas, culturales, etc. Las consecuencias de ello no se dejaron esperar y surgió ese extrañamiento de quienes tuvieron que abandonar España; fue, como dice Ayala, una amputación más dañosa para España misma que para quienes dejaban ésta; pues mejor o peor, con mayor o menor dificultad pudieron salir adelante en los países que los acogieron; eso sí sabiendo que su obra llegaría tarde, en algunos casos quedaría en el olvido, y en todos sería mal conocida por su principal destinatario, el público español, constituyéndose en un capítulo aparte de las artes hispanas.

Pero lo qué para los exiliados era ausencia, para los que permanecían dentro era encierro, aislamiento, una asfixiante atmósfera espiritual. Con estas palabras quizá un poco duras expone Ayala sus ideas sobre este exilio interior:

(8) ILLIE, [2]. 
Con toda energía quiero afirmarlo: la situación de exilio interior no se redujo al padecido por los adversarios del bando triunfador reducidos a soportar su opresión, sino también al de aquellos intelectuales que, encaramados al carro del triunfo o uncidos a su yugo, disfrutaban de los gajes, opulentos o mezquinos, logrados mediante su afiliación. Y creo que, paradójicamente, ese exilio interior afectó del modo más patético a los auténticos fascistas; esto es, al grupo de intelectuales (ciertamente, muy reducido: un grupito en verdad minúsculo) que, con plena convicción y buena fe entusiasta, se incorporaron a un proyecto político cuya realidad no tardaría demasiado en defraudarles (9).

Pero quién sabe, si la lucha por la supervivencia en un medio hostil no es siempre más fuerte que todas las ideas políticas, y muchos de estos exilios se vieron obligados a comulgar con una ideología a la que ni por asomo hubieran apoyado en situaciones normales, de la misma manera que otros se sintieron entusiastas en su comienzo y, al presenciar el cariz que las cosas iban tomando se convirtieron en exiliados tardíos; es muy difícil precisar todos los distintos matices y categorías de las personas que protagonizaron el exilio interior, sin analizar cada una de las circunstancias que concurrieron en sus vidas.

\section{2. ¿PARA QUIÉN ESCRIBEN LOS INTELECTUALES EXILIADOS?}

Volviendo al exilio exterior y más concretamente a las meditaciones que éste suscita en el pensamiento de Ayala, el autor expone en un famoso ensayo el objeto de su preocupación.

Para quién escribimos nosotros fue la reflexión-pregunta que se hizo Francisco Ayala en Buenos Aires en 1948. Desde su exilio bonaerense, Ayala se preguntaba para quién escribía el intelectual español, obligado por el desastre de la guerra civil a ausentarse de España y radicarse en otras tierras, a la espera de que las libertades fueran restituidas y la democracia restablecida. Algunos de sus compañeros de exilio, los que contaron con mayor "ventaja», se asentaron en países de lengua española

(9) Francisco Ayala, "Política y literatura», [5], págs. 307-308.

R. I., 1996, n.o 207 
pudiéndose comunicar en su propio idioma con un público (aunque no su primer destinatario, el pueblo español) más afín a su cultura; frente a aquellos que tuvieron que exiliarse a países de habla inglesa o francesa.

Este ensayo, que fue publicado en 1949 en una revista mexicana (10) y que tuvo una gran repercusión en toda la comunidad exiliada (11), expone los principales temas de interés y preocupación que agitaban las mentes de los intelectuales españoles, obligados al destierro y a la emigración política en América. Hoy, casi medio siglo después de su publicación, vemos cómo la pregunta sigue vigente: ¿para quién escriben los intelectuales españoles o de cualquier otro país del planeta? En un mundo convulsionado como aquél de los años cuarenta, que tuvo como protagonista la Segunda Guerra Mundial, guerra obligada en su intento de acallar las botas del totalitarismo que presionaban a Europa; estableciéndose las negociaciones que sentarían las bases de la Guerra Fría y la política

(10) Francisco Ayala, «Para quién escribimos nostros», Cuadernos Americanos, México, 1949, VIII, XLIII, n. ${ }^{\circ} 1$, págs. 36-58.

(11) La mayoría de los exiliados leyeron con atención este ensayo de Ayala, y algunos vertieron opiniones al respecto, como fue el caso de Pedro Salinas, quien desde su exilio estadounidense en una carta que escribe a su amigo Jorge Guillén hace referencia al citado ensayo. La primera, en una carta fechada en Baltimore el 17 de marzo de 1949, en términos un tanto destemplados: "Has visto un artículo de Ayala en Cuadernos Americanos, sobre los escritores refugiados y sobre quién escriben? Pedantesco, pesado, torpe de estilo, pero toca algunos puntos sensibles. Por lo demás para mí no hay problema: escribo porque escribo.»

En la siguiente carta que Pedro Salinas envía a Jorge Guillén, también desde Baltimore, con fecha de 8 de abril de 1949, vuelve a hacer referencia al presente breve ensayo, esta vez en otros términos (se ve que Pedro Salinas volvió a leerlo y a meditar sobre su contenido): ¿No te hablé del artículo de Ayala en Cuadernos Americanos, titulado 'Para quién escribimos nosotros'. Naturalmente es artículo sociológico, y yo no planteo la cuestión en esos términos, solo. Pero desde el punto de vista que toma me parece interesante y con aciertos.» Pedro Salinas leyó con atención el ensayo ayaliano al que llegó a considerar una declaración de principios sobre la situación de los exiliados en los países de exilio y la posible repercusión de sus obras que comentó además de con Jorge Guillén, con otros exiliados. (Según fuente original, en conversaciones mantenidas con su yerno, Juan Marichal.) Pedro SALINAS y Jorge GuILlÉN, Correspondencia (1923-1951), edición, introducción y notas de Andrés Soria Olmedo, Barcelona, Tusquets, 1992, págs. 492-495. 
de bloques; con una España en pleno apogeo de la dictadura franquistr, ya reconocida y aceptada por muchas naciones; y una Argentina enfervorizada tras las figuras de Perón y Evita... Fue un tiempo de grandes cambios políticos para la humanidad, que el propio Ayala condensa en esta frase: «iAy, cuánta experiencia histórica ha echado sobre nuestros hombros esta larga década!» (12). Hoy también el mundo se agita convulsionado, pese a los enormes cambios y transformaciones que se han sucedido en estas cuatro décadas, iquién lo duda!, pero muchas ideas esbozadas en Para quién escribimos nosotros todavía siguen vigentes y constituyen las eternas preguntas de los intelectuales de todo el mundo.

Este ensayo fue escrito desde la reflexión que supuso para los exiliados el final de la conflagración mundial. Durante la guerra, vivieron con la esperanza de ver cumplida la promesa de restauración en España por parte de los aliados de las libertades perdidas, y el desenlace les sumió en la desesperanza que produjo la aceptación de los vencedores de la dictadura franquista. Después de unos años de vivir entre paréntesis, el intelectual debe seguir produciendo y preguntándose por su ser y destino. Por ello, este ensayo fue el intento de Francisco Ayala de tratar de explicar la función que el intelectual cumple en la sociedad, y las responsabilidades de éste.

Es en el exilio bonaerense donde Ayala se muestra más atento, si cabe, a la realidad que le circunda, fiel observador y fiel sociólogo del mundo en el que vive y de los hombres que lo componen, es en ese marco histórico de la difícil década de los años cuarenta, en el que Ayala llega a preguntarse: ¿para quién escribimos nosotros?, y nosotros: ¿para quién escribe Francisco Ayala, intelectual exiliado en Argentina, sin comunicación con su principal destinatario el público español, y sin posibilidades de publicación -al menos en aquel momento- en su propio país?

La Guerra Civil española fue la causante de esa interrupción de la comunicación entre el intelectual español y su público. Pese a ser un acontecimiento peninsular, en realidad fue un acontecimiento de alcance universal, que afectó en el orden de

(12) Francisco AyAla, «Para quién escribimos...», [5], pág. 213.

R. I., 1996, n.o 207 
la cultura concretamente, a todos los pueblos que participaban del idioma. La cultura que apareció entonces, fue una cultura oficial, que según Ayala, apenas reflejaba más que «oquedad, fachada, propaganda. En todo ello no hay que sorprenderse: al Estado, cualesquiera que sean sus orientaciones, no le interesa la cultura sino como instrumento para sus propios fines, que son en esencia fines políticos» (13).

La guerra civil vino a suspender la actividad intelectual del país; una gran parte, por no decir la mayoría de los hombres que la ejercían, salieron para el exilio a reemprender su trabajo en nuevas circunstancias (el exilio exterior); los que por unas $\mathrm{u}$ otras razones se quedaron (el exilio interior) la reemprendieron con mayores dificultades. $Y$ quienes triunfaron eran aquellos adeptos al régimen, en muchos casos conocidos mediocres:

De este limbo, muchas figuras que por aquel entonces lo eran de pública irrisión, han escalado las posiciones más notorias, son acatadas y abruman a la vida literaria con sus cánones chabacanos. Quien pasee la vista por el panorama de la letra impresa en España durante los últimos tiempos, comprobará la apoteosis lamentable de los mediocres, que no reducidos a producir y publicar -siempre lo hicieron en abundancia-, dan ahora el tono dominante (14).

Para aquellos que eligieron el exilio exterior, y más concretamente los países de América, la recepción fue favorable y se unieron en la esperanza del final de la guerra mundial. «Encontramos, pues, simpatía atenta para cuanto hubiéramos de decir; $\mathrm{y}$ en este sentido el tránsito hacia nuevas condiciones de actuación fue benigno y suave» (15).

Y ese tránsito se les facilitó en la nueva producción editorial, que suspendida en la Península se continúa en dos núcleos capitales, Buenos Aires y México, en conexión estrecha con los intelectuales españoles inmigrados, lo que supuso para ellos: trabajo, canal para expresar sus ideas, enriquecimiento de la cultura del país y base económica para su sustento. El

(13) Ibidem, págs. 198-199.

(14) Ibidem, pág. 199.

(15) Ibidem, pág. 201. 
acceso que tuvieron a Universidades, periódicos y revistas constituyó el soporte necesario para el desenvolvimiento de su actividad intelectual.

A pesar de la exitosa incorporación de los exiliados a las comunidades que los acogieron, que hizo que en muchos casos no tuvieran ni tan siquiera que cambiar de profesión, incluso la mayoría consiguió trabajo, -algunos mejor que el que podrían haber obtenido en España-, y otros hasta fundaron una familia. Pese a todo, no se sienten pertenecientes a su nuevo lugar de residencia, como así lo expresa Jorge Luzuriaga (hijo de exiliados en la Argentina):

Actividad profesional, vínculos familiares, amistades, identificación con la vida pública del país, todo liga al exiliado al lugar de residencia. Pero continúa sin pertenecer a él. Es ésta una sensación a veces consciente, la mayor parte del tiempo soterrada, que le acompaña constantemente, con independencia de su mayor o menor fortuna en el exilio, de la simpatía o el agradecimiento que asienta hacia el país de adopción. Fuera del círculo personal -familia, amistades, colegas-, el país en conjunto no es el suyo. No importa que lo conozca bien en su historia, en su geografía, en sus instituciones; en su aspecto sutil y radical le sigue siendo extraño. (...) Hay, toda una dimensión vacante en el emigrado: la de España. A pesar del tiempo transcurrido, el exiliado sigue buscándola en toda clase de sucedáneos: literatura, cine, otros exiliados (16).

El exiliado, a ciertas horas o ciertos días, deja todas sus actividades para acudir a una tertulia, que sería inverosímil en España por la heterogeneidad de los componentes, pero que tiene un denominador común: todos son españoles, y al final, más tarde o más temprano, sobre España recaerá la conversación. La España de la que cada día se encuentran más desconectados, más distantes, y a la que esperan regresar algún día.

(16) Jorge LuzuriagA, "Sobre el exilio: 1939-1964», Revista de Occidente, Madrid, 1964, mayo, págs. 347-348.

R. I., 1996, n. 207 


\section{CONTINUIDAD DE LA ACTIVIDAD INTELECTUAL}

Una de las formas más utilizadas para continuar la labor intelectual fue la práctica académica, ya que la mayoría de los intelectuales exiliados eran profesores universitarios, además de escritores (17). Y a esta profesionalidad le añadieron su aportación personal de intelectuales y literatos, junto a la exposición divulgadora, la discusión crítica y la traducción de textos extranjeros.

España antes de la Guerra Civil se encontraba en contacto con las corrientes europeas del momento, incluso muchos de sus intelectuales completaron sus estudios en otros países, principalmente Alemania (como en el caso de Ayala) y Francia (18). Ellos divulgaron estas corrientes de pensamiento, primero en España y ahora en Latinoamérica; y tradujeron importantes libros de pensadores europeos, que propagaron las editoriales.

En un principio el trasvase cultural -según Francisco Ayala- a los países de habla hispana venía desde España, que era quien se mantenía en contacto con los grandes centros científicos europeos, y difundía las últimas novedades a todos los países del idioma español.

En esa función difusora de cultura, Ayala destaca el trabajo de los traductores españoles, quienes no sólo traducen las obras sino que también aportan sus conocimientos con los comentarios que añaden a éstas:

Al comunicar mediante la traducción a nuestro público, con los consiguientes comentarios e influencias diversas, mu-

(17) La actividad docente fue para muchos exiliados la forma más habitual de ganarse el sustento, hasta el punto que en ningún otro período de la historia del exilio español hubo tantos profesores. Como ejemplo de ello, están los poetas de la generación del 27 a los que Juan Ramón Jiménez con cierta sorna llamaba los poetas-profesores.

(18) Muchos de nuestros exiliados se sienten agradecidos, y con razón, a la visión de futuro que tuvo la Junta de Ampliación de Estudios al otogar becas para el extranjero, a quienes constituirían lo más granado de nuestra intelectualidad. Y así estas becas posibilitaron un viaje de estudios a Ortega a Alemania, a Francisco Ayala al mismo país, a Pedro Salinas a Francia, etc., Ayala hace referencia a esta beca y su estancia en Berlín, en su libro de memorias: Memorias y olvidos, Madrid, Alianza, Tres, 1988. 
chas de esas elaboraciones, se prolongaba su existencia eficiente en el momento mismo que la irrupción totalitaria y, en seguida, la destrucción militar obturaban las vías de su natural desenvolvimiento en Europa (19).

Es entonces, cuando los Estados Unidos, aprovechando en cierta forma la coyuntura favorable recupera esa tradición intelectual mediante las Universidades -y la aportación de los exiliados europeos- incorporándola a su cultura:

Aquella recuperación e incorporación a que Norteamérica se aplicara respecto de las adquisiciones culturales capaces de inmediata conversión práctica y susceptibles de repercusión técnica aprovechable a fines útiles, la ha cumplido a su vez Hispanoamérica, en cierta medida, para los valores más sutiles de la cultura. Y no podrá negarse que tal medida hubiera sido muy inferior sin el refuerzo de la emigración intelectual española (20).

Ayala procura huir del sentimiento de nostalgia que produce la patria abandonada, pese a lo lacrimógena que pueda ser la propia condición de exiliado, que ha convertido el destierro en algunos casos en incesante peregrinación. Aún así se encuentran en alguna parte, en países desde cuya perspectiva se les muestra el conjunto. Y si además, es un país de América de habla hispana, la comunidad de cultura fundada por el idioma le ofrecerá al intelectual emigrado posibilidades para desarrollar su pensamiento, que debe aprovechar, gracias a las favorables condiciones del medio ambiente en el que ahora trabaja.

Esta reflexión le lleva a establecer la comparación con otros colegas asentados en otros países con distinta lengua: Estados Unidos, Inglaterra, Francia, etc., quienes se sintieron extranjeros, pensando y produciendo en otra lengua, de forma muy diferente a quien vivió y trabajó en Latinoamérica, que "sólo con apoyarse en los elementos de la comunidad local, abierta para él hasta cierto punto, y desde cuyo seno puede

(19) Francisco Ayala, «Para quien escribimos nosotros», [5], pág. 203.

(20) Idem. 
hacerse oír, puede actuar en alguna medida como hombre de pensamiento" (21).

Pero hay también una desventaja siempre presente y a la par lógica, la acomodación psicológica del exiliado frente a la realidad histórica por la tradicional dilucidación del problema «España: su ser y destino», que quedó cortado con la Guerra Civil:

Esta guerra fue una colosal y trágica orquestación del tema, y su demostración por la prueba del hierro y del fuego: la causa española, España, irrumpió de golpe en un orden mundial del que era arrabal inerte, para perturbarlo y plantearle al Occidente su cuestión moral en términos tan perentorios, tan obstinados y violentos, que se haría para él cuestión de vida o muerte, de salvarse o condenarse (22).

Ayala se refiere a la limitación en que los exiliados se encuentran, no sólo la constituida por la realidad del presente histórico, sino también la que dimana de su situación de intelectuales españoles emigrados en América. Limitación que hace referencia a la vigencia de los sentimientos nacionalistas desarrollados en los lugares en los que habitan, y que van unidos a los propios sentimientos nacionalistas, en su corazón de españoles.

\section{La ACOGIDA A LOS EXILIADOS ESPAÑOLES}

Sobre la acogida dispensada a los españoles, y las facilidades o dificultades que imponen los gobiernos, o el pueblo, se han escrito muchas páginas; la cantinela repetida de la buena o mala acogida de tal o cual país, significa para Ayala un caso de retórica muy extendida pero vacía de contenido:

Mucha, y muy florida, y muy sentimental retórica es la que se ha derrochado acerca de la generosidad con que los países hispanoamericanos recibieron a quienes, terminada la

(21) Ibidem, pág. 207.

(22) Ibidem, pág. 208. 
guerra civil con la derrota de la República, debimos abandonar la patria amada, fugitivos de Franco. Cuando de generosidad o de otras virtudes morales se trata, entiendo yo que es más propicio referirse a personas individuales, a seres humanos concretos, que no a colectividades. De otro modo, se incurre en el riesgo de dar expresión al vacío. Lo de la hospitalidad generosa con que tal o cual país acogió a los exiliados españoles es, ha llegado a ser, un lugar común que, como tantos otros tópicos, cualquiera que fuere su base de realidad, resulta en útimo análisis falso, y hasta un poco irritante. En mi personal experiencia, tengo yo que agradecer a varios amigos su buena voluntad, su generosa disposición de ánimo en circunstancias tales o cuales; pero frente a los países donde he vivido no me creo obligado a la menor gratitud ni, por supuesto, autorizado tampoco a emitir la menor queja. Según me parece a mí, lo que en cada caso proporciona -o al contrario, cicatea o aún niega- oportunidades de vida al recién llegado, sea como simple emigrante, sea como refugiado político, son las condiciones objetivas en que el país en cuestión se halle en el momento dado (23).

En el caso de los exiliados españoles la peor o mejor acogida por parte de los diferentes países de habla hispana vino determinada por varios factores, entre los que es cierto que jugaron a su favor la simpatía política a la causa republicana, las afinidades ideológicas, y en el plano personal la suerte y el destino; aunque desde luego el factor más importante vino determinado por la coyuntura económica del país de acogida en ese momeno. En general, estos factores apuntados se cumplieron en México, y no es mera coincidencia que fuera el país que recibió más exiliados, gracias a que en ese preciso instante se encontraba en una fase de crecimiento económico, y los exiliados que acudieron, muchos de ellos profesionales liberales, significaron una valiosa aportación en un país en creciente expansión, aunque todavía con ciertas deficiencias como en el campo de la educación al que tanto contribuyeron; el factor de simpatía ideológica vino determinado por el apoyo que a estos exiliados proporcionó el gobierno de Lázaro Cárdenas. Otro país que tuvo el empeño de acoger exiliados españoles fue la República

(23) Francisco AyalA, «El exilio», [18], págs. 257-258.

R. I., 1996, n. ${ }^{\circ} 207$ 
Dominicana, presidida en esos momentos por el dictador Leónidas Trujillo:

De quién hubiera sido ridículo sospechar simpatía hacia la causa de la República española, y sarcástico el pretender atribuirle un corazón tierno y compasivo, tuvo muy especial empeño (...) en acoger, o recoger, en su isla al mayor número posible de españoles refugiados. Y aunque hubo resistencia a aceptar la hospitalidad que se adelantaba a brindarnos, y a la postre no fueron hacia ellá tantos como él hubiera deseado, a la llegada del grupo los saludó con una estimulante alocución a la que pondría término exhortándolos para que aplicaran sus energías a la tarea de blanquear la raza (24).

Aunque fue un grupo reducido el que se exilió en la República Dominicana, y no todos los que hubiera deseado Trujillo, entre ellos se encontraban españoles de gran renombre como: Vicente Lloréns, Eugenio F. Granell, Javier Malagón, Segundo Serrano Poncela, Vicente Herrero, Jesús Galíndez, etc. En el caso argentino, aunque el factor económico no era desfavorable, en principio el gobierno de Ortiz no propició la admisión a los exiliados; todo lo contrario, se les pusieron bastantes trabas a la entrada al país, eso ayudó a que México fuera el lugar por excelencia en acogida y el que mayor número de exiliados concentró; pero pese a todas las dificultades, Argentina se constituyó en el segundo país de importancia en acogida, tanto en cantidad como por la calidad de los intelectuales que allí se establecieron, por nombrar sólo algunos: Niceto AlcaláZamora, Claudio Sánchez Albornoz, Luis Jiménez de Asúa, Lorenzo Luzuriaga, José Ortega y Gasset, Alfonso Rodríguez Castelao, Luis Seoane, Maruja Mallo, Pío del Río Ortega, Rafael Alberti, $\mathbf{M}^{\mathrm{a}}$ Teresa León, etc.

Pese a que Ayala considera ridícula la tan manida literatura que nos refiere a la favorable o desfavorable aceptación de tal o cual país, es cierto que unos gobiernos ofrecieron más facilidades que otros a la hora de recibir exiliados, aunque eso sí, fueron las individualidades las que les brindaron su apoyo y su ayuda a los exiliados particularmente, siendo cada situación

(24) Ibidem, págs. 258-259. 
personal, por lo que nunca podemos hablar de los exiliados como un conjunto homogéneo de personas; porque no lo eran, sólo les une -y no es poco- la circunstancia del exilio. Por ello, las reacciones hacia su nueva situación y su nuevo país son diferentes en cada caso:

Y si las atenciones que cada uno puede haber recibido, los obsequios, los beneficios, se atribuyen, como es de razón, a la estimación, la simpatía o la amistad de las personas que en efecto los dispensan, y sólo por una vaga figura de dicción 'al país', ¿cómo acusar a éste, en cambio, de las dificultades, inconvenientes o tropiezos que uno pueda haber sufrido? Pero es grato sentirse protector a tan nula costa; y, en la desdicha, consuela el tener de quien quejarse. (...) Españoles hay que, forzados a vivir fuera de España proclaman, sin embargo, muy convencidos, la superioridad intrínseca de su triste patria -con mayor lógica tendrían que juzgarla cruel e inicua-, en detrimento de los demás países: perciben para el propio las relaciones concretas de que su personal infortunio dimana, y a éstos los condenan en bloque, sin discriminación, y tal vez sin mejor causa que ese infortunio, tan ajeno a ello después de todo. (...) Dignidad irritada y un despecho muy comprensible explican la chocante agresividad nacionalista que, en este punto, hace reaccionar a muchos emigrados españoles, cualquiera que sea su expresa y confesa ideología, como verdaderos fascistas (25).

Esa reacción muy común viene provocada por un fuerte impacto de las ideas nacionalistas, que deben enfrentar en la emigración -no nos olvidemos que nos encontramos en la década de los años cuarenta-, hombres adultos y ya formados, que tienen que rehacer su vida en un nuevo ambiente; en el caso argentino, en plena expansión peronista con toda su fanfarria de: himnos, banderas, héroes y padres de la patria; si la cortesía los trata de gratos huéspedes, es mientras no medien intereses opuestos, competencias, diferendos, envidias, resquemores privados o enconos políticos, si esto ocurre entonces pasarían de gratos huéspedes a huéspedes ingratos. Y es que pese a toda la retórica florida de la buena acogida de los

(25) Francisco Ayala, "Para quién escribimos...», [5], págs. 209-210. 
países, el exiliado no deja de ser un emigrado, un extranjero en el nuevo país, y debe conducirse con cuidado para no comportarse como un huésped ingrato para el país y las gentes que lo recibieron.

Pero también hay que reconocer que ese nacionalismo se enfrenta con las dificultades propias de la emigración; el desplazamiento de hombres adultos, con sus propias realidades pujantes, que van a rehacer su vida en un nuevo ambiente. Y entre ellos se encuentran los escritores, quienes deben hurgar en la sociedad del país, en su realidad política; pero deben obrar con cautela, porque en el fondo son extranjeros, son huéspedes. El escritor ejerce su oficio en la publicidad y debe tocar registros de la vida pública, hurgar en las zonas sensibles, pero siempre con la máxima cautela, sabiéndose extranjero. Aunque Ayala afirma hoy con la perspectiva que proporciona el paso del tiempo, que él nunca se sintió un huésped: "yo siempre he escrito sobre la realidad política argentina estando allí, y después, yo nunca me he inhibido por ningún motivo; cuando creí que debía decir una cosa la he dicho» (26).

En contraposición con la idea de huésped se reafirma en el exiliado ese nacionalismo imperante en el mundo en general, apoyado por el devenir histórico, que hace que el español vea su patria como un paraíso perdido, y el latinoamericano -y por ende el argentino- vea la suya para bien o para mal, como cosa propia, donde el exiliado se ve amenazado del castigo de intruso:

El escritor español en América se cree cohibido y obligado por sus antecedentes de emigrado político a una reserva, a un lujo de precauciones que hacen sibilinos, reticentes o vagorosos sus escritos, no tienen más aguzada punta ni agarran con mayor brío la realidad inmediata los escritos que, junto a los suyos, publican intelectuales del país a quienes no amenaza el palmetazo, castigo de intrusos (27).

Por ello Ayala se pregunta: «¿Qué ocurre, pues? ¿Tal vez pesan sobre éstos inhibiciones análogas? Pienso que, en cierto sentido, sí; que ese nacionalismo desaforado, causa activa y

(26) Entrevista con Francisco Ayala, 12 de agosto de 1992.

(27) Francisco Ayala, «Para quién escribimos...», [5], pág. 211. 
pasiva de serias limitaciones a nuestra labor, limita igualmente la de cualesquiera escritores, como síntoma que es, en su propio exceso, de la general descomposición que desconcierta a todo el mundo» (28).

Ayala también se pregunta: ¿Quién está hoy libre en él de posible falla a los ojos del perfecto patriota? No olvidemos que en el año que se escribe este ensayo, en el caso concreto de Argentina, Perón ocupaba la presidencia obtenida gracias a los resultados de las urnas que le otorgaron como claro vencedor en 1946. El peronismo se encontraba en pleno apogeo, todavía no se había producido el desencanto que tuvo lugar en la segunda presidencia, y muchos argentinos -no sólo «los descamisados»- seguían sin réplica la política de gobierno protagonizada por Perón y Evita. Por eso, Ayala contesta a su pregunta exponiendo ese nacionalismo (a ultranza, aunque disfrazado) que él, como los demás exiliados, y el pueblo argentino están viviendo, donde todos son sospechosos: uno por ser judío, el otro por extranjero, aquél por socialista, etc. «En resumidas cuentas, todo el que no sea un resuelto partidario del gobierno atrae la sospecha de pertenecer, dentro de la nación, al partido nefando e impreciso de la antipatria» (29).

Y si eso ocurre en Argentina, donde «la llegada del peronismo, si bien es cierto que afectó al país entero y a todo el mundo que estaba allí, no así afectó de lleno a la expresión pública, no estableció unas limitaciones oficiales. Hubo sí, una presión ambiental desagradable, pero presión del ambiente, presión social» (30). Qué no ocurrirá en España, donde la presión no sólo es social sino también oficial, y donde la expresión pública sufre el corte de la censura. «Sí: bien mirado, las interdicciones que pesan sobre el escritor español en el exilio no le son peculiares; menores que las sufridas por sus colegas en España, pesan también sobre todos los demás escritores. Pues,

(28) Ibidem, págs. 211-212.

(29) Ibidem, pág. 212.

(30) Entrevista con Francisco Ayala, 12 de agosto de 1992.

Esta presión ambiental, que hoy expresa después de cuarenta años de forma tan benévola, sí que influyó, y así lo refleja en otros ensayos, a la hora de abandonar el país en 1950.

\section{R. I., 1996, n.o 207}


bien mirado, todos los escritores viven hoy en el exilio, donde quiera que vivan» (31).

\section{La España Cautiva y la EsPaña PEREgrina}

Y hay otro autor, el escritor literario, el autor de ficciones poéticas, cuya orientación es sobre todo hacia el valor estético. En principio puede parecer que éste no tiene el problema de la expatriación, ya que depende de su propia virtud creadora, y además tiene la fortuna de escribir en un idioma que se extiende por el mundo más allá de las fronteras políticas del Estado español. Y al dirigirse a las zonas íntimas del pensamiento, al mundo de la imaginación, puede parecer que está exento de la servidumbre de instancias intermedias; pero esto no es así. $\mathrm{Si}$ el ensayista se ve desconectado del plexo social originario, también la invención literaria se encuentra desgajada de su propio ambiente. El escritor emigrado se encuentra desconectado o desgajado de la comunidad donde se formó y privado del destinatario fundamental de sus escritos, el público español. Por tanto, el escritor ha sido desgajado de España y España ha sido desgajada de él, por el mismo golpe del destino.

La historia prosigue y el escritor se va adaptando a su nuevo país, vive fuera del suyo, y con el tiempo, el país propio y él llegan a extrañarse recíprocamente. Vive aparte, toma distancia, y al volver "se encuentra con que han mudado las cosas -nunca las cosas cesan de mudar-, y en seguida, al reflexionar sobre sí mismo, descubre que él ha sufrido entre tanto mutaciones que le alejan, no de las cosas tal cual ahora son; más aún: de las cosas como eran y como las recuerda en su anterior estado» (32).

"Nuestro alejamiento ha sido episodio de una censura en la continuidad nacional que, si arrancó de cuajo a los escritores que emigraron, fue ocasión de operar en el país transformaciones tales como para que los otros, los que allí debieron

(31) Frase dura ésta, teñida de cierta desesperanza. Francisco Ayala, «Para quién...», [5], pág. 212.

(32) Ibidem, págs. 214-215. 
quedarse, no sufrieran menos violenta alteración en sus condiciones de trabajo, sometidos a un Estado que, haciendo indeciblemente precarias las expresiones de la originalidad creadora, le fuerce a observar recaudos, que terminan por morder en el ánimo más templado y torcer la más lúcida mente o silenciarla. Esta situación, que es, con todo, la situación actual de su país, el escritor exiliado ni la ha vivido ni la padece en su propia carne» (33). Esta censura en la continuidad nacional no la padece sólo el exiliado -exterior- la padece tanto o más, el exiliado interior.

En los primeros años del exilio se esperaba que todo fuera transitorio, que en poco tiempo se retornarían las libertades perdidas y ellos regresarían a la anhelada España. Pero no fue así, y hoy huelga decir, que la esperanza puesta en el final de la Segunda Guerra Mundial y el triunfo de los aliados se convirtió en desesperanza, al no ayudar éstos a restituir en España la democracia. Es por lo que Ayala llega a decir que durante ese período su existencia, y la de los demás exiliados, "ha sido pura expectativa, un absurdo vivir entre paréntesis» (34). Por ello, rotas las esperanzas puestas en el final de la guerra mundial, el escritor debe volver los ojos a la realidad que le circunda, de una forma positiva, y la mejor forma de ello es seguir escribiendo, seguir produciendo en el exilio. «El problema, pues, consiste en cómo retomar ahora en nuestras manos, digerida tan terrible experiencia, la dirección de nuestra propia vida de escritores, tal cual ésta se nos da, dentro de circunstancias cuyo marco no podemos alterar, pero sobre cuyo fondo debemos actuar con los medios que nos son peculiares; es decir, dentro de las circunstancias de la emigración y asiéndonos a ellas con toda resolución y energía; pues la emigración pertenece de lleno, lejos de ser un accidente inconsiderable y accesorio, al destino de la literatura española, como le pertenece -lo que no es sino la otra faz de este mismo destino- el cautiverio de España; pues si hay una llamada España peregrina es, precisamente, porque hay una España cautiva» (35).

(33) Ibidem, pág. 215.

(34) Ibidem, pág. 216.

(35) Ibidem, pág. 218.

R. I., 1996, n.o 207 
En orden a la producción literaria Ayala recomienda entregarse a ella con plenitud espiritual, dejar de un lado la nostalgia y alimentarla de su situación presente. Ponerse manos a la obra, y crearla con la aceptación que la experiencia ha querido proporcionarle al artista en vivencias que no debe echar de lado, y que se encuentran insertas en la realidad que la ha tocado vivir:

«De nada vale cerrar los ojos a la realidad y prescindir de ella, borrarla de la imaginación (...); equivale al suicidio. Si no deseamos incurrir en él, si hemos de intentar salvarnos salvando la continuidad de las letras españolas, tenemos que ponernos a elaborar literariamente las inmediatas cosas que la realidad en cuyo centro nos hallamos instalados ofrece a nuestros ojos; cosas inmediatas o lejanas vivencias, o fantasías, o puros elementos de la subjetividad (...), pero, eso sí, en todo caso desde el centro de la más rigorosa, concreta y tensa conciencia de actualidad»(36).

En esa realidad que les circunda los exiliados no pueden olvidarse nunca del tema España, de las dos Españas, la peregrina y la cautiva, la fugitiva de sí misma y la aherrojada, ambas se anhelan entre sí, víctimas de un mismo destino. Y quienes menos deben olvidarlo son ellos, los emigrados, los exiliados; que si por un lado son: los fuertes, los afortunados, los privilegiados que cuentan con ventajas; por otro lado son: horriblemente débiles, una prole independiente, una especie a extinguir. Por ello, propone como salvación la escritura, como lenguaje universal, canal en el que se unen los espíritus letrados, en puro combate frente a la sordidez mental en que han caído los iletrados.

Y se encuentran todavía con otro problema a resolver, no de menor importancia, el acceso al público. Todo lo que se escribe está hecho con vistas a un lector, y se espera alcanzar con el mensaje el ámbito de resonancias más atinado posible. Ahora,

no se escribe igual, como es notorio, cuando ello ha de pasar por una censura cuyas miradas se conocen y cuyos criterios

(36) Ibidem, págs. 219-220. 
se calculan, que cuando puede encaminársele libremente en procura de afinidades, curiosidad o simpatía en la incógnita multitud; ni cuando prevalece un ambiente social, que cuando es otro el que domina. De modo consciente o inconsciente, el escritor se atempera; rechaza unos asuntos y se acoge a otros; elige sus puntos de partida, establece el sistema de sus referencias y decide el sesgo de presentación de su tema, según las características de su público (37).

No se pide una libertad omnímoda, porque es difícil que ésta llegue a darse, pero sí que las barreras se relajen y cedan a su paso.

Tanto el Francisco Ayala de 1948 como el de hoy, y como él cualquier intelectual lúcido comprometido con el mundo y la época que le ha tocado vivir, escribe desde su atalaya, en una reflexión solitaria, en la contemplación y la meditación de unos hechos históricos que se suceden a tal velocidad que es difícil expresar a dónde nos conducen. Hoy también vivimos en la expectación y la espera, y muy pocos intelectuales son capaces no sólo de predecir el futuro que nos aguarda, sino de analizar desde una perspectiva coherente y razonada el propio presente.

Las ideas esbozadas desde el exilio, cuando el intelectual ha perdido tras una guerra civil su propia patria y con ella su ser y destino en el mundo, ino son las mismas ideas que exponen los intelectuales exiliados de los países de la Europa del Este, los latinoamericanos que buscan un lugar en España -como hace tan sólo cincuenta años lo hicieran los españoles en América-, los magrebíes en Europa, y tantos otros pueblos que esperan -como Ayala y sus compañeros de exilio esperabanver restablecidas la libertad y la democracia en sus países de origen? Por ello, este ensayo, que tan bien refleja la época en que fue escrito y la condición humana, cuarenta años después vuelve a encontrarse en plena actualidad, ya que éstas y otras palabras solamente son para el hombre, como dice Francisco Ayala: «una reflexión solitaria, un reflejo del mundo en el espejo de mi conciencia.»

(37) Ibidem, págs. 221-222.

R. I., 1996, n.o 207 
Through a discussion of Francisco Ayala's thinking - a Spanish writer who lived in exile in Argentina in the 1940s- the author analyzes the condition and concept of exile from the point of view of the intellectual who is forced to live and work away from his country, thereby losing contact with the main recipient of his writings: the Spanish public. 